\title{
Photorefractive keratectomy in patients with mild to moderate stable keratoconus: a five-year prospective follow-up study
}

This article was published in the following Dove Press journal:

Clinical Ophthalmology

25 September 2013

Number of times this article has been viewed

\author{
Elias Chelala' \\ Hala El Rami' \\ Ali Dirani' \\ Ali Fadlallah' \\ Omar Fakhoury' \\ Elias Warrak ${ }^{2}$ \\ 'Saint-Joseph University, Faculty of \\ Medicine, ${ }^{2}$ Clemenceau Medical \\ Center, Beirut, Lebanon
}

Correspondence: Ali Fadlallah

Saint-Joseph University, Faculty of Medicine, Rue de Damas, B.P. I I-5076 Riad El Solh, Beirut II 07 2180, Lebanon Tel +96| | 42| 000

Email fadlallahmd@gmail.com
Background: The purpose of this study was to evaluate the visual outcome of photorefractive keratectomy (PRK) in patients with mild to moderate stable keratoconus and to assess the risk of progression of the disease after the excimer laser procedure.

Methods: In this prospective study, carried out at the Clemenceau Medical Center, an affiliate of Johns Hopkins International, in Beirut, Lebanon, 119 eyes from 72 patients with grade 1-2 keratoconus (Amsler-Krumeich classification) underwent PRK. Forty-seven patients had both eyes treated and 25 patients had one eye treated. The procedure was done using the Wavelight Eye Q Excimer laser. Uncorrected and best-corrected visual acuity, corneal topography, and pachymetry were assessed before the procedure and 3, 6, 12, 36, and 60 months after the procedure.

Results: Mean uncorrected visual acuity showed a statistically significant improvement $(P<0.05)$ at one, 3 , and 5 years follow-up. One hundred and seventeen eyes $(98.3 \%)$ showed no progression while two eyes $(1.7 \%)$ showed progression of the disease at 5 years follow-up, as documented by corneal topography and pachymetry. These two eyes were treated with corneal collagen crosslinking.

Conclusion: PRK in mild to moderate keratoconus is a safe and effective procedure for improving uncorrected vision in patients with mild refractive errors. However, close follow-up of patients is needed to detect any progression of the disease. Longer follow-up is needed to assess the overall effect of this procedure on progression of the disease.

Keywords: stable keratoconus, photorefractive keratectomy

\section{Introduction}

Keratoconus is a noninflammatory, progressive, and degenerative disease of the cornea characterized by central thinning and increased corneal curvature. The decrease in visual acuity is moderate to severe. It is due to myopia and irregular astigmatism and, at advanced stages, corneal scarring. Many clinical and surgical options for visual rehabilitation of keratoconus are available, ie, glasses, contact lenses (soft, rigid gas permeable, rigid, sclera, and semiscleral), intracorneal ring segments, phakic intraocular lenses, and keratoplasty (penetrating or lamellar) in advanced stages. ${ }^{1}$

The unique conservative treatment option for keratoconus is still the fitting of rigid contact lenses to improve quality of vision, which is usually precarious with eyeglasses. Being a disease of the young, contact lens intolerance is a major issue through the years, with the risk of infectious keratitis. The consequences of the latter can be dramatic in already diseased corneas. 
Other treatment options are corneal rings. Rings could reduce steepening and improve vision in carefully selected topography cases, especially in those patients experiencing contact lens discomfort. ${ }^{2,3}$ On the other hand, collagen crosslinking of the anterior stroma by the photosensitizer riboflavin and ultraviolet A light laser is being used for managing progressive keratoconus. ${ }^{4-6}$ In advanced keratoconus with scarring or hydrops, classic penetrating and lamellar keratoplasty are the mainstay of treatment. ${ }^{7}$ The newer less invasive lamellar keratoplasty is an appealing option offering better graft tolerance compared with penetrating keratoplasty. ${ }^{8-10}$

Refractive surgery in patients with such irregular corneas has long been contraindicated because of the risk of postoperative progression of the disease process. This is especially true with laser in situ keratomileusis. The flap created in laser in situ keratomileusis weakens the corneal tissue and renders the cornea more prone to keratectasia. ${ }^{11}$ However, numerous studies claim the safety of surface ablation in suspected keratoconus or in "forme fruste keratoconus" as in photorefractive keratectomy (PRK) and in PRK followed by corneal collagen crosslinking. ${ }^{12-14}$

The purpose of this study was to assess the visual outcome of PRK done in patients with mild to moderate stable keratoconus and to evaluate the safety of the procedure in terms of progression of the disease process.

\section{Patients and methods}

This was a prospective study that enrolled stable keratoconic patients during the period from January 2006 to December 2008. Participation rate in the study was $0.82(82 \%)$ and the loss to follow-up rate was $0.22(22 \%)$.

Diagnosis of keratoconus was based on a combination of the Pentacam ${ }^{\circledR}$ (Oculus Optikgerate GmbH, Wetzlar, Germany) of the anterior and posterior corneal surfaces, keratometric readings, and corneal pachymetry. ${ }^{15-18}$ All the patients had mild refractive errors (defined by a manifest refraction requiring a maximum ablation depth of $50 \mu \mathrm{m}$ and leading to a minimal residual corneal thickness of $450 \mu \mathrm{m}$ ), a best-corrected visual acuity (BCVA) superior or equal to 20/30, and grade 1 or 2 keratoconus according to the AmslerKrumeich keratoconus classification system (grade 1, eccentric corneal bulging, myopia, and/or astigmatism $<5 \mathrm{D}$ and corneal radius $\leq 48 \mathrm{D}$, no corneal opacities; grade 2 , myopia and/or astigmatism $>5 \mathrm{D}$ and $<8 \mathrm{D}$ and/or corneal radius $\leq 53 \mathrm{D}$, no central opacities, pachymetry $\geq 400 \mu \mathrm{m}) .{ }^{19}$ All patients were uncomfortable using either eyeglasses or rigid contact lenses and their refraction was stable for at least one year prior to surgery. A complete ophthalmic examination including dilated fundus examination was done. Other ocular pathologies were ruled out. Exclusion criteria were: central corneal thickness less than $450 \mu \mathrm{m}$ (measured by optical pachymetry, Oculus Pentacam), corneal opacification/scars, history of keratitis (any form), peripheral marginal degeneration, previous corneal and/or intraocular surgeries, and autoimmune and/or connective tissue disease.

The risks and benefits of the surgery were discussed with the patients, who gave their written informed consent. This study was approved by the review board committee at Clemenceau Medical Center, an affiliate of Johns Hopkins International in Beirut, Lebanon. One hundred and nineteen eyes were treated: 47 patients had both eyes treated and 25 patients had one eye treated. PRK was done at Clemenceau Medical Center. All surgical procedures were done by the same surgeon (EW). The laser treatment was carried out under local anesthesia (oxybuprocaine hydrochloride $0.4 \%$ ). The central $9 \mathrm{~mm}$ of corneal epithelium was removed by application of $20 \%$ ethyl alcohol on the cornea for 25-30 seconds, followed by copious irrigation with a balanced salt solution. A dry Merocel sponge was used to peel off the epithelium. A standard non-topoguided PRK with a 5.5-6 mm optical zone and a transition zone of less than $2 \mathrm{~mm}$ was performed in all eyes with maximum ablation depth set at $50 \mu \mathrm{m}$. Residual corneal thickness was $\geq 450 \mu \mathrm{m}$. Laser treatment was carried out using the wavefront-optimized Wavelight ${ }^{\circledR}$ Eye Q Excimer laser (Allegretto ${ }^{\circledR}$, [Alcon Laboratories Inc, Fort Worth, TX, USA] with an ablation rate of $400 \mathrm{~Hz}$, $0.95 \mathrm{~mm}$ [0.68 mm full width at half maximum] Gaussian laser beam, and $400 \mathrm{~Hz}$ active eye-tracker). Mitomycin $\mathrm{C}$ $0.2 \%$ was applied for 20 seconds after laser treatment to minimize postoperative haze. Soft contact lens wearing was kept and patients maintained on tobramycin and dexamethasone sodium phosphate $0.1 \%$ (Tobradex ${ }^{\circledR}$, Alcon Laboratories Inc) eyedrops four times daily for 10 days. Fluorometholone eyedrops were then prescribed for 3 months with progressive tapering.

Measured parameters were uncorrected visual acuity (UCVA), BCVA, spherical equivalent refraction, and cylindrical component. All were assessed before the procedure and at 3, 6, 12, 36, and 60 months afterwards. Haze was graded using the system described by Fantes et al ( 0 , no haze; +0.5 , trace haze on oblique illumination; +1 , corneal cloudiness not interfering with the visibility of fine iris details; +2 , mild effacement of fine iris details; +3 and +4 , details of the lens and iris not discernible). ${ }^{20}$ 
Corneal topography and pachymetry were also performed using the Oculus Pentacam before the procedure and at 6 , 12, 36, and 60 months afterwards. Progressive keratoconus was defined by an increase in the cone apex keratometry of $0.75 \mathrm{D}$ or an alteration of $0.75 \mathrm{D}$ in the spherical equivalent refraction in the last 6 months.

\section{Statistical analysis}

Statistical analysis was performed using the Statistical Program for Social Sciences version 13.0 software (SPSS Inc, Chicago, IL, USA). A paired $t$-test was used to compare the preoperative and postoperative characteristics of patients. A $P$-value $<0.05$ was considered statistically significant.

\section{Results}

Seventy-two patients (40 males and 32 females) with keratoconus and of mean age $31.5 \pm 8.4$ (19-54) years were included in the study. The logarithm of the minimum angle of resolution (logMAR) for UCVA and BCVA was $0.76 \pm 0.34$ and $0.018 \pm 0.007$, respectively. Spherical error and cylinder varied between $+2.00 \mathrm{D}$ and $-5.75 \mathrm{D}$ and between $0.50 \mathrm{D}$ and $3.00 \mathrm{D}$, respectively. $\mathrm{K}$ flat (keratometry in the flat meridian) and $\mathrm{K}$ steep (keratometry in the steep meridian) varied between 39.5 D and 52.2 D and between 40.1 D and 54.2 D, respectively. Remaining preoperative patient characteristics are presented in Table 1.

\section{Refractive results}

Mean UCVA showed a statistically significant improvement at one, 3 , and 5 years follow-up. Seventy-nine eyes $(66.3 \%)$ had a UCVA of 20/20 at 5 years follow-up and 119 eyes $(100 \%)$ had a UCVA $>20 / 40$ at 5 years follow-up. Mean BCVA remained stable postoperatively (Figure 1). Two eyes $(1.7 \%)$ lost two or more lines at 5 years follow-up. The mean spherical error and mean cylindrical component obtained from manifest refraction also showed a statistically significant improvement throughout the follow-up period. A total of 101 eyes $(84.9 \%)$ had a manifest spherical equivalence within $0.50 \mathrm{D}$ and $1.00 \mathrm{D}$ at 5 years and two of the eyes $(1.7 \%)$ had a manifest refraction change of more than $1.00 \mathrm{D}$ at 5 years.

\section{Topographic results}

$\mathrm{K}$ flat and $\mathrm{K}$ steep decreased significantly postoperatively and remained stable during the follow-up period (Figure 2). One hundred and seventeen eyes (98.3\%) showed no progression of the disease, and two eyes (1.7\%) showed progression at 5 years follow-up as documented by corneal topography. Progression was evident in two eyes from two different patients. The first patient, aged 33 years, had a BCVA of 20/25, with $-2.25+1.25 \mathrm{D}$ manifest refraction, a central corneal thickness of $492 \mu \mathrm{m}$, and a $\mathrm{K}_{\max }$ of $47.8 \mathrm{D}$. Keratoconus progression was evident at one-year follow-up, with an increase in maximum keratometry of $1.12 \mathrm{D}$. The second patient, aged 29 years, had a BCVA of 20/20, with $-1.75+1.50 \mathrm{D}$ manifest refraction, a central corneal thickness of $502 \mu \mathrm{m}$, and a $\mathrm{K}_{\text {max }}$ of $48.1 \mathrm{D}$. Keratoconus progression was evident at 2-year follow-up, with an increase in maximum keratometry of 1.22 D. The two eyes were treated subsequently by collagen crosslinking, with a final UCVA at

Table I Refractive, keratometric, and topographic results

\begin{tabular}{|c|c|c|c|c|c|c|}
\hline & Baseline & One month & 6 months & One year & 3 years & 5 years \\
\hline UCVA logMAR & $0.76 \pm 0.34$ & $0.11 \pm 0.02$ & $0.06 \pm 0.01$ & $0.04 \pm 0.009$ & $0.046 \pm 0.008$ & $0.036 \pm 0.009$ \\
\hline$P$ versus baseline & & $<0.01$ & $<0.01$ & $<0.01$ & $<0.01$ & $<0.01$ \\
\hline $\begin{array}{l}\text { BCVA logMAR } \\
P \text { versus baseline }\end{array}$ & $0.018 \pm 0.007$ & $\begin{array}{l}0.06 \pm 0.008 \\
(0.782)\end{array}$ & $\begin{array}{l}0.026 \pm 0.002 \\
(0.8 I I)\end{array}$ & $\begin{array}{l}0.031 \pm 0.003 \\
(0.703)\end{array}$ & $\begin{array}{l}0.022 \pm 0.002 \\
(0.6015)\end{array}$ & $\begin{array}{l}0.027 \pm 0.003 \\
(0.801)\end{array}$ \\
\hline $\begin{array}{l}\text { Spherical error } \\
P \text { versus baseline }\end{array}$ & $-2.75 \pm 2.13$ & $\begin{array}{l}-0.9 \pm 0.18 \\
(0.01)\end{array}$ & $\begin{array}{l}-0.85 \pm 0.17 \\
(0.01)\end{array}$ & $\begin{array}{l}-0.77 \pm 0.15 \\
(0.01)\end{array}$ & $\begin{array}{l}-0.79 \pm 0.19 \\
(0.01)\end{array}$ & $\begin{array}{l}-0.76 \pm 0.19 \\
(0.01)\end{array}$ \\
\hline $\begin{array}{l}\text { Cylinder } \\
P \text { versus baseline }\end{array}$ & $1.23 \pm 0.62$ & $\begin{array}{l}0.55 \pm 0.2 \\
(0.01)\end{array}$ & $\begin{array}{l}0.49 \pm 0.12 \\
(0.01)\end{array}$ & $\begin{array}{l}0.51 \pm 0.19 \\
(0.01)\end{array}$ & $\begin{array}{l}0.52 \pm 0.21 \\
(0.01)\end{array}$ & $\begin{array}{l}0.48 \pm 0.13 \\
(<0.01)\end{array}$ \\
\hline $\begin{array}{l}C C T \\
P \text { versus baseline }\end{array}$ & $524 \pm 28$ & $\begin{array}{l}489 \pm 32 \\
(0.01)\end{array}$ & $\begin{array}{l}491 \pm 29 \\
(0.02)\end{array}$ & $\begin{array}{l}484 \pm 31 \\
(0.01)\end{array}$ & $\begin{array}{l}488 \pm 27 \\
(0.01)\end{array}$ & $\begin{array}{l}492 \pm 34 \\
(0.02)\end{array}$ \\
\hline $\begin{array}{l}\mathrm{K}_{\max } \\
P \text { versus baseline }\end{array}$ & $47.1 \pm 3.6$ & $\begin{array}{l}45.4 \pm 3.3 \\
(0.01)\end{array}$ & $\begin{array}{l}45.6 \pm 3.6 \\
(0.01)\end{array}$ & $\begin{array}{l}45.9 \pm 3.2 \\
(0.01)\end{array}$ & $\begin{array}{l}45.7 \pm 3.4 \\
(0.01)\end{array}$ & $\begin{array}{l}45.4 \pm 3.8 \\
(0.01)\end{array}$ \\
\hline $\begin{array}{l}K \text { flat } \\
P \text { versus baseline }\end{array}$ & $43.8 \pm 1.9$ & $\begin{array}{l}42.1 \pm 1.7 \\
(0.01)\end{array}$ & $\begin{array}{l}41.9 \pm 1.5 \\
(0.01)\end{array}$ & $\begin{array}{l}41.7 \pm 2.1 \\
(0.01)\end{array}$ & $\begin{array}{l}41.8 \pm 2.2 \\
(0.01)\end{array}$ & $\begin{array}{l}42.2 \pm 2.1 \\
(0.02)\end{array}$ \\
\hline $\begin{array}{l}K \text { steep } \\
P \text { versus baseline }\end{array}$ & $45.4 \pm 2.3$ & $\begin{array}{l}43.8 \pm 2.5 \\
(0.01)\end{array}$ & $\begin{array}{l}43.5 \pm 2.2 \\
(0.01)\end{array}$ & $\begin{array}{l}43.8 \pm 2.5 \\
(0.01)\end{array}$ & $\begin{array}{l}43.6 \pm 2.2 \\
(0.01)\end{array}$ & $\begin{array}{l}43.9 \pm 2.6 \\
(0.01)\end{array}$ \\
\hline
\end{tabular}

Abbreviations: CCT, central corneal thickness; UCVA, uncorrected visual acuity; BCVA, best-corrected visual acuity; logMAR, logarithm of the minimum angle of resolution. 


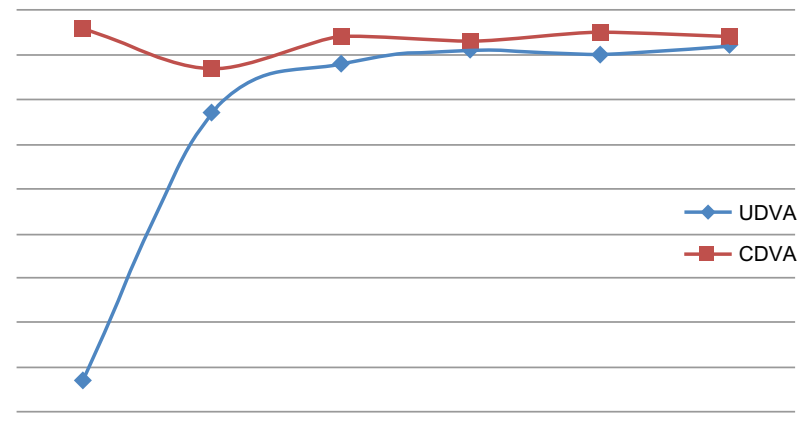

Figure I Change in UDVA and CDVA (in decimals) over the follow-up period. Abbreviations: UDVA, uncorrected distance visual acuity; CDVA, corrected distance visual acuity.

5 years of 20/30 and 20/40, respectively, and a final BCVA at 5 years of $20 / 25$ and $20 / 30$, respectively.

\section{Postoperative subepithelial opacity}

The majority of eyes showed a subepithelial opacity below grade 2 at different time intervals. Eight eyes had grade 2 haze at one-month follow-up, one eye had grade 2 haze at 6 months follow-up, and no eye had grade 2 haze (or higher) at 5 years follow-up.

\section{Discussion}

In patients with mild to moderate keratoconus, combined PRK and collagen crosslinking has been proven to be a safe and effective alternative to correct minor refractive error, stabilizing the remaining stromal bed and avoiding progression of ectatic disease. ${ }^{13,14,20}$

Guedj et al reported 62 eyes of 42 patients with suspected keratoconus who were treated with PRK alone. Postoperatively, visual acuity improved significantly and remained stable during a follow-up period of 5 years.

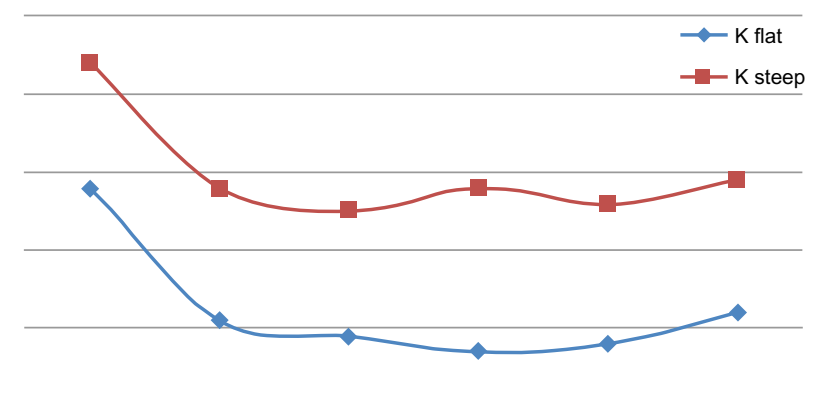

Figure 2 Change in keratometry over the follow-up period.
Treatment with PRK alone did not lead to progression or acceleration of the suspected keratoconus or any other complication. ${ }^{12}$

According to our results and the literature, PRK seems to be a promising option for the rehabilitation of eyes with mild refractive errors and a $B C V A \geq 20 / 30$, especially when coupled with contact lens intolerance. ${ }^{21-24}$ To avoid the complications associated with collagen crosslinking (mainly haze), we choose not to perform collagen crosslinking at baseline and to postpone it as much as possible. During the follow-up period, patients had a corneal topography every 6 months in the first year then annually. Of the 119 eyes included in the study, only two eyes had progression and were subsequently treated with collagen crosslinking.

Accurate thresholds for a safe ablation regarding parameters such as $\mathrm{K}$ readings and pachymetry are not yet established. Kasparova and Kasparov recommend $>500 \mu \mathrm{m}$ central and peripheral corneal thickness. ${ }^{25}$ Koller et al also recommend a minimal corneal thickness $>500 \mu \mathrm{m}$ and predicted residual corneal thickness $>450 \mu \mathrm{m}$ with maximal $\mathrm{K}$ reading $<49 .{ }^{22}$ In the study by Cennamo et al, maximal $\mathrm{K}$ readings were $52.09 \pm 3.47 .{ }^{24}$ Overall keratoconus severity ranged from forme fruste to a maximum grade 2 keratoconus according to the Amsler-Krumeich classification, with stable refraction of at least one year in most studies. ${ }^{11,22,23,26-28}$

Haze was the most frequently reported complication in the literature. In most studies, mitomycin $\mathrm{C}$ was not used during surgery. Kasparova and Kasparov reported haze in $5 / 70$ eyes in the early postoperative period. ${ }^{25}$ This disappeared in $1-3$ months with the use of corticosteroids. In the study by Cennamo et al, haze was 0 in 22 eyes and 0.5 in four eyes at 24 months follow-up. ${ }^{24}$ Haze was grade 1 in $3 / 4$ eyes treated by Doyle et al and grade 2 in $1 / 4$ eyes. ${ }^{28}$ The latter patient was given fluorometholone. In the study by Bahar et al, $20 \%$ of eyes had grade I haze that disappeared following 3 months of steroids and $7.5 \%$ had grade II haze that partially regressed following steroids. ${ }^{27}$ In our study, we used mitomycin $\mathrm{C}$ in all patients and haze was not a major concern (eight patients had grade II haze at one month follow-up). At the end of our follow-up, no patients had any vision-impairing haze.

In the studies reviewed, refractive results were comparable with those in our study, with significant improvement of UCVA, BCVA, and manifest refraction postoperatively. ${ }^{11,22,26}$ In the study by Kasparova and Kasparov, keratoconus progression appeared in $6 / 70$ eyes $(8.57 \%)$ in the first to sixth month after surgery. ${ }^{25}$ This was identified as increased myopia and myopic astigmatism and reduction of corneal thickness. In our study, only $2 / 119$ eyes (1.7\%) showed progression at 
5 years follow-up. The mean age in our study was 31.5 years, which renders progression less likely and could explain this difference. In the other studies reviewed, no progression of keratoconus was observed during the follow-up period. Topographies done at regular intervals showed notable reduction of steepening and irregularity. ${ }^{11,22,24,25,27,28}$ However, a longer follow-up period is needed. For instance, Koller et al suggest corneal topography monitoring for up to 5 years to be sure that the photorefractive keratectomy has not induced keratoconus progression in corneas documented to be preoperatively stable for years. ${ }^{22}$ In fact, corneal ectasia can occur even a decade after PRK. ${ }^{29}$

In some studies, PRK even seems to halt the progression of keratoconus. Cennamo et al reported a significant decrease in all keratoconus indices during 24 months of follow-up of treated eyes $(n=25)$ versus an increase in indices in control untreated eyes $(n=8)$, suggesting a possible therapeutic effect of excimer laser, halting the progression of keratoconus. ${ }^{24}$ A larger population and longer follow-up is warranted. It is speculated that excimer laser ablation leads to formation of a new fibrocellular membrane instead of the ablated corneal layers. The rigidity of this membrane is much higher than the anterior corneal layers in keratoconus so that better biomechanical qualities of the new membrane could act like a shield that helps to prevent further progression of keratoconus. At the same time, the fibrocellular membrane can serve as the matrix for synthesis and reconstruction of the lamellar structure, characteristic of a normal cornea. Both processes would theoretically prevent keratoconus progression in the postoperative period. ${ }^{25}$

PRK seems to be a good therapeutic option for patients with mild to moderate stable keratoconus and bad uncorrected visual acuity, low refractive errors, and contact lens intolerance. Significant visual improvement was reached in our study and is reported in the literature. It is reasonably safe, with little risk of disease progression in carefully selected patients. Our results are restricted to a 5-year study period, and safety over a longer follow-up must be assessed to ensure the safety of such an approach in treating patients with stable keratoconus.

\section{Conclusion}

Combined PRK and collagen crosslinking have been proven to be a safe and effective procedure for correcting minor refractive error and stabilizing the cornea in keratoconus. PRK alone with regular follow-up could be a safe and effective procedure for improving uncorrected vision in selected patients with mild to moderate stable keratoconus.

\section{Disclosure}

The authors report no conflicts of interest in this work.

\section{References}

1. Fadlallah A, Dirani A, Rami HE, Cherfane G, Jarade E. Safety and visual outcome of Visian Toric ICL implantation after corneal collagen cross-linking in keratoconus. J Refract Surg. 2013;29:84-89.

2. Piñero DP, Alió JL, Teus MA, Barraquer RI, Michael R, Jiménez R. Modification and refinement of astigmatism in keratoconic eyes with intrastromal corneal ring segments. J Cataract Refract Surg. 2010;36: $1562-1572$.

3. Pesando PM, Ghiringhello MP, Di Meglio G, Romeo S. Treatment of keratoconus with Ferrara ICRS and consideration of the efficacy of the Ferrara nomogram in a 5-year follow-up. Eur J Ophthalmol. 2010;20: 865-573.

4. Goldich Y, Marcovich AL, Barkana Y, Avni I, Zadok D. Safety of corneal collagen cross-linking with UV-A and riboflavin in progressive keratoconus. Cornea. 2010;29:409-411.

5. Vinciguerra P, Albè E, Trazza S, Seiler T, Epstein D. Intraoperative and postoperative effects of corneal collagen cross-linking on progressive keratoconus. Arch Ophthalmol. 2009;127:1258-1265.

6. Caporossi A, Mazzotta C, Baiocchi S, Caporossi T. Long-term results of riboflavin ultraviolet A corneal collagen cross-linking for keratoconus in Italy: the Siena Eye Cross Study. Am J Ophthalmol. 2010;149: 585-593.

7. Fukuoka S, Honda N, Ono K, Mimura T, Usui T, Amano S. Extended long-term results of penetrating keratoplasty for keratoconus. Cornea. 2010;29:528-530.

8. Tan DTH, Anshu A, Parthasarathy A, Htoon HM. Visual acuity outcomes after deep anterior lamellar keratoplasty: a case-control study. Br J Ophthalmol. 2010;94:1295-1299.

9. Javadi MA, Feizi S, Yazdani S, Mirbabaee F. Deep anterior lamellar keratoplasty versus penetrating keratoplasty for keratoconus: a clinical trial. Cornea. 2010;29:365-371.

10. Feizi S, Javadi MA, Jamali H, Mirbabaee F. Deep anterior lamellar keratoplasty in patients with keratoconus: big-bubble technique. Cornea. 2010;29:177-182.

11. Bühren J, Schäffeler T, Kohnen T. Preoperative topographic characteristics of eyes that developed posoperative LASIK keratectasia. J Refract Surg. 2013;29:540-549.

12. Guedj M, Saad A, Audureau E, Gatinel D. Photorefractive keratectomy in patients with suspected keratoconus: five-year follow-up. J Cataract Refract Surg. 2013;39:66-73.

13. Kymionis GD, Portaliou DM, Kounis GA, Limnopoulou AN, Kontadakis GA, Grentzelos MA. Simultaneous topography-guided photorefractive keratectomy followed by corneal collagen cross-linking for keratoconus. Am J Ophthalmol. 2011;152:748-755.

14. Krueger RR, Kanellopoulos AJ. Stability of simultaneous topographyguided photorefractive keratectomy and riboflavin/UVA cross-linking for progressive keratoconus: case reports. J Refract Surg. 2010;26: S827-S832.

15. Fam H-B, Lim K-L. Corneal elevation indices in normal and keratoconic eyes. J Cataract Refract Surg. 2006;32:1281-1287.

16. Maeda N, Klyce SD, Smolek MK. Comparison of methods for detecting keratoconus using videokeratography. Arch Ophthalmol. 1995;113: 870-874.

17. Quisling S, Sjoberg S, Zimmerman B, Goins K, Sutphin J. Comparison of Pentacam and Orbscan IIz on posterior curvature topography measurements in keratoconus eyes. Ophthalmology. 2006;113: 1629-1632.

18. Rabinowitz YS, Rasheed K, Yang H, Elashoff J. Accuracy of ultrasonic pachymetry and videokeratography in detecting keratoconus. J Cataract Refract Surg. 1998;24:196-201.

19. Alió JL, Shabayek MH. Corneal higher order aberrations: a method to grade keratoconus. J Refract Surg. 2006;22:539-545. 
20. Fantes FE, Hanna KD, Waring GO 3rd, Pouliquen Y, Thompson KP, Savoldelli M. Wound healing after excimer laser keratomileusis (photorefractive keratectomy) in monkeys. Arch Ophthalmol. 1990;108: 665-675.

21. Stojanovic A, Zhang J, Chen X, Nitter TA, Chen S, Wang Q. Topography-guided transepithelial surface ablation followed by corneal collagen cross-linking performed in a single combined procedure for the treatment of keratoconus and pellucid marginal degeneration. J Refract Surg. 2010;26:145-152.

22. Koller T, Iseli HP, Donitzky C, Ing D, Papadopoulos N, Seiler T. Topography-guided surface ablation for forme fruste keratoconus. Ophthalmology. 2006;113:2198-2202.

23. Alpins N, Stamatelatos G. Customized photoastigmatic refractive keratectomy using combined topographic and refractive data for myopia and astigmatism in eyes with forme fruste and mild keratoconus. J Cataract Refract Surg. 2007;33:591-602.

24. Cennamo G, Intravaja A, Boccuzzi D, Marotta G, Cennamo G. Treatment of keratoconus by topography-guided customized photorefractive keratectomy: two-year follow-up study. J Refract Surg. 2008;24:145-149.
25. Kasparova EA, Kasparov AA. Six-year experience with excimer laser surgery for primary keratoconus in Russia. J Refract Surg. 2003; 19(Suppl 2):S250-S254.

26. Wygledowska-Promieńska D, Gierek-Ciaciura S. Eight year results of excimer laser correction for irregular astigmatism by linear excimer laser photoablations of the cornea in cases of keratoconus. Klin Oczna. 2000;102:439-442. Polish.

27. Bahar I, Levinger S, Kremer I. Wavefront-supported photorefractive keratectomy with the Bausch and Lomb Zyoptix in patients with myopic astigmatism and suspected keratoconus. J Refract Surg. 2006;22:533-538

28. Doyle SJ, Hynes E, Naroo S, Shah S. PRK in patients with a keratoconic topography picture. The concept of a physiological "displaced apex syndrome". Br J Ophthalmol. 1996;80:25-28.

29. Kim H, Choi JS, Joo CK. Corneal ectasia after PRK: clinicopathologic case report. Cornea. 2006;25:845-848.
Clinical Ophthalmology

\section{Publish your work in this journal}

Clinical Ophthalmology is an international, peer-reviewed journal covering all subspecialties within ophthalmology. Key topics include: Optometry; Visual science; Pharmacology and drug therapy in eye diseases; Basic Sciences; Primary and Secondary eye care; Patient Safety and Quality of Care Improvements. This journal is indexed on

\section{Dovepress}

PubMed Central and CAS, and is the official journal of The Society of Clinical Ophthalmology (SCO). The manuscript management system is completely online and includes a very quick and fair peer-review system, which is all easy to use. Visit http://www.dovepress.com/ testimonials.php to read real quotes from published authors. 